NBER WORKING PAPER SERIES

TRENDS IN INTERGENERATIONAL INCOME MOBILITY

\author{
Chul-In Lee \\ Gary Solon
}

Working Paper 12007

http://www.nber.org/papers/w12007

\author{
NATIONAL BUREAU OF ECONOMIC RESEARCH \\ 1050 Massachusetts Avenue \\ Cambridge, MA 02138 \\ January 2006
}

The authors are grateful for comments from Anders Bjorklund, Nathan Grawe, Steven Haider, Thomas Hertz, Patrick Kline, Bashkar Mazumder, and seminar participants at the University of Michigan, Stanford University, and the National Bureau of Economic Research. The views expressed herein are those of the author(s) and do not necessarily reflect the views of the National Bureau of Economic Research.

(C2006 by Chul-In Lee and Gary Solon. All rights reserved. Short sections of text, not to exceed two paragraphs, may be quoted without explicit permission provided that full credit, including (C) notice, is given to the source. 
Trends in Intergenerational Income Mobility

Chul-In Lee and Gary Solon

NBER Working Paper No. 12007

January 2006

JEL No. D31, D63, J31

\begin{abstract}
Previous studies of recent U.S. trends in intergenerational income mobility have produced widely varying results, partly because of large sampling errors. By making more efficient use of the available information in the Panel Study of Income Dynamics, we generate more reliable estimates of the recent time-series variation in intergenerational mobility. Our results, which pertain to the cohorts born between 1952 and 1975, do not reveal major changes in intergenerational mobility.

Chul-In Lee

Department of Economics

Konkuk University

1 Hwayang-dong

Kwangjin-gu

Seoul, 143-701

Korea

leeci@konkuk.ac.kr

Gary Solon

Department of Economics

University of Michigan

Ann Arbor, MI 48109

and NBER

gsolon@umich.edu
\end{abstract}




\section{Trends in Intergenerational Income Mobility}

\section{Introduction}

Over the last fifteen years, a large body of new research has documented that the intergenerational transmission of economic status in the United States is much stronger than had been suggested by earlier sociological and economic analyses. More recently, several researchers have begun to investigate trends in intergenerational mobility. Researchers, public policy analysts, and journalists have been particularly interested in whether the large rise in income inequality that has occurred over the last quarter-century has been accompanied by a decline in intergenerational mobility. ${ }^{1}$

The research conducted so far on intergenerational mobility trends has produced wildly divergent estimates. In this paper, we argue that this confusing array of evidence is partly an artifact of imprecise estimation, which in turn has stemmed from inefficient use of the available data. By drawing more fully on the information in the Panel Study of Income Dynamics, we generate more reliable estimates of the recent time-series variation in intergenerational mobility. For the most part, these estimates do not reveal major changes in intergenerational mobility.

In the next section, we briefly summarize the theoretical and empirical literatures on trends in intergenerational mobility. In section III, we describe our approach to utilizing the available data more fully, and we present our results.

\footnotetext{
${ }^{1}$ See Solon (1999) for a survey of the intergenerational mobility literature and Chadwick and Solon (2002) and Mazumder (2005) for more recent studies. Popular interest in mobility trends is typified by Bernstein (2003), Wooldridge (2005), Wessel (2005), and Scott and Leonhardt (2005).
} 


\section{Previous Literature}

The classic analysis by Becker and Tomes (1979) provides a foundation for theoretical consideration of intergenerational mobility trends. After adapting the BeckerTomes model to rationalize the log-linear intergenerational income regression commonly estimated in empirical research, Solon (2004) uses the model to explore the reasons that the intergenerational income elasticity might vary over time and place. The adapted model assumes that parents divide their income between their own consumption and investment in their children's human capital so as to maximize a Cobb-Douglas utility function in which the two goods are parental consumption and child's later income. The child's income is a return to the child's human capital, which depends on investments by the government (e.g., through public provision of education or health care) as well as by the parents. The child's human capital also includes an endowment that is correlated across generations because of both genetic and cultural inheritance of income-related traits.

Analysis of the model's steady state shows that the intergenerational income elasticity depends positively on both the earnings return to human capital investment and the heritability of income-generating traits, and it varies inversely with the progressivity of government investment in children's human capital. The model also can be used to investigate the short-run (i.e., first-generation) impact of perturbations from the steady state. For example, the intergenerational elasticity becomes higher following an increase in the earnings return to human capital. If the recent rise in earnings inequality is interpreted largely as an increase in returns to human capital (Katz and Autor, 1999), then the model accords with the often-stated conjecture that increasing inequality might be 
accompanied by declining intergenerational mobility. On the other hand, the model also indicates that the intergenerational elasticity would decline with an increase in the progressivity of public investment in children's human capital. Mayer and Lopoo (2004, 2005) argue that American children growing up since the initiation of the War on Poverty have indeed experienced more progressive government investment in education, health, and nutrition. ${ }^{2}$ If so, the trend in intergenerational mobility becomes theoretically ambiguous. Which factor has dominated - rising returns to human capital or more progressive public investment in children - is an empirical question.

Several researchers have begun to address the empirical question, but the evidence so far has been mixed and confusing. For example, Mayer and Lopoo (2005) use the Panel Study of Income Dynamics (PSID) to estimate the intergenerational income elasticity for each cohort of sons born between 1949 and 1965. For each cohort, the elasticity is estimated in the year that the cohort is 30 years old. Thus, the elasticity estimate for the year 1990 is based only on the cohort born in 1960 and ignores the 1990 data for all other cohorts. Looked at another way, the elasticity estimate for the 1960 cohort uses the cohort's earnings in only 1990 and ignores the 1960 cohort's earnings in all other years. The resulting point estimates show a large downward trend in the intergenerational elasticity, but they are so imprecise that the estimated trend is statistically insignificant. $^{3}$

\footnotetext{
${ }^{2}$ In his Ely Lecture to the American Economic Association, Welch (1999, p. 16) makes a related conjecture: “. . in the last three decades of increasing wage dispersion, if we had seen reduced intergenerational mobility and increased differentiation in economic status between Americans of African and European ancestry and between men and women, I suspect that most of us would not be sanguine about the accomplishments of the period. The evidence is not available regarding intergenerational mobility, but when it is, I believe we will find that it has increased."

${ }^{3}$ The estimates imply that the elasticity declined from 0.41 for the 1949 cohort to 0.28 for the 1965 cohort. After estimating the time series of intergenerational elasticities for the 1949-1965 cohorts, Mayer and Lopoo arbitrarily reestimate the trend for the 1953-1965 cohorts, for whom the negative trend estimate has
} 
Fertig (forthcoming) uses the PSID to estimate intergenerational earnings elasticities for both sons and daughters. Compared to Mayer and Lopoo, she uses a much narrower time frame: five five-year windows starting with 1985-1989 and ending with 1989-1993. Unlike Mayer and Lopoo, Fertig does not restrict her observation of sons' and daughters' earnings to only one age. Once she proceeds to trend estimation, however, she becomes concerned about the implications of repeated observations for her standard error estimation, and she randomly discards four out of the five time windows for each individual. Most of her trend estimates indicate declining intergenerational elasticities, but most are too imprecise to be statistically significant.

Levine and Mazumder (2002) use the National Longitudinal Surveys (NLS) and the General Social Survey (GSS) as well as the PSID. With the NLS and PSID, they estimate intergenerational elasticities for sons in the 28-36 age range in 1980 and in one year in the early 1990's, thus ignoring sons' earnings data in all other years. With the GSS, they pool the 1976-1984 data as the first period and the 1989-1994 data as the second. Levine and Mazumder's PSID results, like some of those of Mayer and Lopoo and Fertig, show a large but statistically insignificant decline (from 0.45 to 0.29 ) in the estimated intergenerational elasticity. In contrast, their NLS estimates show a statistically significant increase from 0.22 to 0.41 . This result, however, may be distorted by the differential reporting of parental income between the two periods. In the later period, parental income was self-reported; in the earlier period, it was reported by the sons. The GSS estimates also indicate an increase in the intergenerational elasticity, but the estimated increase is not statistically significant.

an absolute $t$-statistic greater than 2. In a similar analysis for daughters, Mayer and Lopoo (2004) initially estimate an insignificantly positive trend, after which they restrict to the 1949-1960 cohorts to obtain a significantly positive estimate of the trend. 
A common feature of these and other studies ${ }^{4}$ is sparseness of data. Some studies focus on only a few years, in some instances only two. Some studies span more years, but use only one year's data per individual, discarding most of the available information on each individual. The resulting estimates are highly imprecise. Some of the studies estimate large increases in intergenerational mobility, some estimate large decreases, and most of the estimated changes are statistically insignificant.

In the next section, we reanalyze the PSID in a way that uses all available years for each sampled son and daughter. By making more efficient use of the available data, we are able to obtain more reliable estimates of changes in intergenerational mobility over time.

\section{New Evidence}

\section{A. Data}

The PSID, administered by the University of Michigan's Survey Research Center, is a longitudinal survey that began in 1968 with a national probability sample of almost 5,000 U.S. families. The PSID sample has been reinterviewed every year through 1997 and every other year since then. Each year's survey collects annual income data for the preceding calendar year. The PSID has been a great resource for intergenerational research because it has followed children from the original sample as they have grown into adulthood and formed their own households. It therefore is possible to relate the

\footnotetext{
${ }^{4}$ See also Reville (1995), Corcoran (2001), Nam (2004), Chadwick (2004), and Blanden (2004). For examples of studies that analyze socioeconomic status measures other than income, see Hauser (1998) and Harding, Jencks, Lopoo, and Mayer (2005). In research carried out concurrently with ours, Hertz (2005) also makes more complete use of the available PSID data. Despite numerous differences in sample selection criteria and model specification, he obtains results qualitatively similar to ours.
} 
children's income status as adults to the status of their parents as reported by the parents themselves since the outset of the survey. ${ }^{5}$

Our analysis pertains to sons and daughters born between 1952 and 1975. Children born before 1952, who were older than 16 at the 1968 interview, are excluded to avoid overrepresenting children who left home at late ages. Because we need the sons' and daughters' adult income observations to be at least somewhat informative about their longer-run income, we use income observed no earlier than age 25. Consequently, the first year in which we observe children's income is 1977 (as reported in the 1978 interview), the year when the 1952 cohort reached age 25. In 1978, we use income data on the 1952 cohort (then age 26) and the 1953 cohort (age 25). By 2000, the last year for which we have children's income data (as reported in the 2001 interview), the children's ages range from 25 for the 1975 cohort to 48 for the 1952 cohort.

Thus, our data on children's income in each year are observed over a range of ages, and the range changes over time. This raises the question of how to control for the children's age variation. Mayer and Lopoo $(2004,2005)$ do so by using observations at only age 30 , but that approach throws out most of the available data. Our alternative approach is to retain the available data, but to include detailed age controls in our econometric specification, which is presented in the next subsection.

Like Mayer and Lopoo, we measure the children's adult income by the family income in the household in which they have become the head or head's spouse. We exclude income observations imputed by "major assignments." We also exclude outlier observations for which income (in 1967 dollars as measured by the CPI-U) is less than

\footnotetext{
${ }^{5}$ The PSID is not well suited for studying intergenerational mobility in immigrant families that had not yet arrived in the United States as of the survey's initiation. For studies of immigrant mobility based on other data, see Borjas (1993) and Card, DiNardo, and Estes (2000).
} 
$\$ 100$ or more than $\$ 150,000$. We use only the Survey Research Center component of the

PSID. We exclude the Survey of Economic Opportunity component (the so-called "poverty sample") because the serious irregularities in that sample's selection make it impossible to ascertain what population the sample represents. ${ }^{6}$

\section{B. Econometric specification}

Most of the empirical research on intergenerational income mobility attempts to measure the intergenerational elasticity in long-run income, i.e., the slope coefficient in the regression of child's log long-run income on parents' log long-run income. In practice, however, no intergenerational data set contains lifetime income data on both generations, so empirical researchers use short-run income measures to proxy for longrun income, and they control for the life-cycle stage of both children and parents at the times their incomes are observed.

Like many previous studies, ours uses a multi-year measure of parental income. In particular, we average log annual family income over the three years when the child was 15-17 years old. For example, for sons and daughters in the 1952 cohort, the parental income variable is for the years 1967-1969 (as reported in the 1968-1970

\footnotetext{
${ }^{6}$ See Charles Brown's memo available at http://psidonline.isr.umich.edu/Publications/Papers/SEO.pdf. The SEO sample selection problems recounted there (in Brown's characteristically understated style) are too numerous to repeat here. The problem we find most disturbing is that, for reasons that remain unknown to this day, the computer consulting firm in Washington, DC that the Office of Economic Opportunity hired to select low-income households from the Census Bureau's 1967 Survey of Economic Opportunity sample failed to include most of the eligible households in the lists it transmitted to the Survey Research Center. Worse yet, the omissions clearly were not random. Brown's memo notes a racial pattern - the transmission rate was 55 percent for non-whites and 21 percent for whites. A passage he quotes from the Survey Research Center's 1984 PSID User Guide also refers to "substantial" variation across geographic areas. That passage concludes, "By the time we realized that not all the addresses of the 'signers' had been forwarded, the Census personnel knowledgeable about the process had moved on to designing the 1970 Census, and OEO personnel were not able to provide us any information. Our repeated efforts to secure more information about the lost cases were not successful."
} 
interviews). ${ }^{7}$ We apply the same sample restrictions for parental income as described at the end of the previous subsection for children's income. Also, to account for the differences among the sample parents in how old they were when their children were 1517 , we control for a quartic in the average age of the household head over those years. ${ }^{8}$ As discussed by Solon (1989), Mazumder (2005), and Haider and Solon (forthcoming) among others, using a short-run measure of parental income to proxy for the key regressor induces a downward errors-in-variables bias in the estimation of the intergenerational elasticity in long-run income. As long as this bias is approximately stable over time, however, it will not seriously distort our estimation of changes in intergenerational mobility. ${ }^{9}$

The dependent variable in the intergenerational regression equations we estimate is the son's or daughter's log annual family income in years ranging from 1977 to 2000 and at ages ranging from 25 to 48 . As a proxy for the child's log long-run income, this variable also is subject to measurement error. Based on the classical errors-in-variables model discussed in almost every introductory econometrics textbook, researchers often assume that "left-side" measurement error causes no bias in least squares estimation of regression models. Grawe (forthcoming) and Haider and Solon (forthcoming), however, explain why the textbook model does not apply in the present context. Because of systematic heterogeneity across individuals in their rates of income growth over the life cycle, the measurement error in log current income as a proxy for log lifetime income is

\footnotetext{
${ }^{7}$ Our choice of the 15-17 age range is dictated by data availability. For the 1952 cohort, we cannot observe parental income any earlier.

${ }^{8}$ See Murphy and Welch (1990) on the advisability of flexible functional forms for life-cycle income profiles.

${ }^{9}$ Despite the rise in income inequality over our sample period, the noise-to-signal ratio in log current income as a proxy for log long-run income might have stayed about the same if the variances of the persistent and transitory components of log income increased in similar proportion. According to the estimates in Gottschalk and Moffitt (1994) and Haider (2001), that was indeed the case.
} 
mean-reverting early in the life cycle and mean-departing later on. The source of this pattern is that individuals with high lifetime income tend to have steeper income growth trajectories. As a result, the current income gap early in the life cycle between those who will eventually have high lifetime income and those who will end up with low lifetime income understates the lifetime gap, and the current income gap later in the life cycle overstates the lifetime gap. This is why Reville (1995) and many other researchers have found that they estimate lower intergenerational elasticities when the sons' or daughters' incomes are measured early in the life cycle. To account for this pattern in a sample in which we measure children's income over ages ranging from 25 to 48 , we must control not only for the child's age, but also for the interaction of child's age with parental income. $^{10}$

Thus, for sons and daughters separately, we apply ordinary least squares to the regression model

$$
\begin{aligned}
y_{i c t}= & \alpha^{\prime} D_{t}+\beta_{t} X_{i c}+\gamma_{1} A_{i c}+\gamma_{2} A_{i c}^{2}+\gamma_{3} A_{i c}^{3}+\gamma_{4} A_{i c}^{4}+\delta_{1}(t-c-40) \\
& +\delta_{2}(t-c-40)^{2}+\delta_{3}(t-c-40)^{3}+\delta_{4}(t-c-40)^{4}+\theta_{1} X_{i c}(t-c-40) \\
& +\theta_{2} X_{i c}(t-c-40)^{2}+\theta_{3} X_{i c}(t-c-40)^{3}+\theta_{4} X_{i c}(t-c-40)^{4}+\varepsilon_{i c t}
\end{aligned}
$$

where $y_{i c t}$ is $\log$ family income in year $t$ for child $i$ in birth cohort $c=1952,1953, \ldots$,

1975. With the PSID interviews switching to every other year near the end of our sample

\footnotetext{
${ }^{10}$ Our estimated coefficients for the interaction terms accord with the previous studies' finding of smaller elasticity estimates when son's income is measured early in the life cycle. In our sample, in which the sons get older over the years, failing to account for this pattern would lead to spurious estimation of an upward time trend in intergenerational elasticities. The pattern for our daughters sample is less clear-cut.
} 
period, the vector $D_{t}$ contains year dummy variables for each $t=1977,1978, \ldots, 1996$,

1998, 2000. The key explanatory variable $X_{i c}$ is the parental log income variable

described above. Because our main purpose is to study change over time in

intergenerational mobility, the coefficient $\beta_{t}$ varies with year. As discussed above, the

regression includes controls for a quartic in parental age $A_{i c}$ at the time parental income

is observed, a quartic in child's age $t-c-40$ at the time child's income is observed, and interactions of the child's age quartic with parental income. The child's age variable $t-c-40$ is normalized to equal zero at age 40 . This simplifies interpretation of the $\beta_{t}$ vector, which expresses how the intergenerational elasticity at child's age 40 evolves as successive cohorts pass through that age. ${ }^{11}$ Later, when we plot how our estimates of $\beta_{t}$ change over time, the normalization to age 40 will affect only the height of the plotted estimates, not the variation over time.

It is well known that time, age, and cohort effects cannot be separately identified without imposing strong functional form restrictions. ${ }^{12}$ For example, when observing intergenerational income elasticities when the offspring are age 30, the comparison between the 1950 and 1951 birth cohorts is necessarily the same thing as the comparison between the years 1980 and 1981. In this paper, we make the arbitrary choice to label trends in terms of years, recognizing that, since we are controlling for age, the same trends might just as well be labeled in terms of cohorts. In a similar research project carried out concurrently with ours, Hertz (2005) makes the opposite arbitrary choice to

\footnotetext{
${ }^{11}$ The results in Haider and Solon (forthcoming) suggest that the errors-in-variables bias from non-classical "left-side" measurement error in child's log current income as a proxy for log long-run income is inconsequential if current income is measured at around age 40.

${ }^{12}$ See section 2.7 in Deaton (1997) for a thorough discussion.
} 
label intergenerational mobility trends in terms of cohorts. In either case, the estimated trends should be interpreted as reflecting a combination of time and cohort trends. Not surprisingly, his results are much the same as ours. In his words, "I have already detailed the differences between my approach and that of Lee and Solon, but it bears emphasizing that our qualitative conclusions are similar: if we include the full range of birth cohorts there does not appear to be strong evidence of a trend in the IGE [intergenerational elasticity]...."

Our main specification shown as equation (1) assumes that the income/age trajectories of different cohorts have the same shape. The inclusion of year dummy variables allows the height of the trajectories to vary across cohorts (or, equivalently, across years), but otherwise the coefficients of all variables involving child's age are assumed to be common across cohorts. ${ }^{13}$ Later, we will discuss the robustness of our results to relaxing that restriction.

Our estimation of equation (1) is based on unbalanced panel data in which we use repeated observations of the same individuals. Our sons sample contains 11,230 observations of 1,228 individuals, and our daughters sample contains 12,666 observations of 1,308 individuals. Thus, our samples average almost 10 observations per individual and about 50 individuals for each of the 24 cohorts born between 1952 and 1975 . The latter highlights why studies using only one cohort per year (or, equivalently, one year per cohort) obtain very imprecise estimates.

Positive autocorrelation of the error term $\varepsilon_{i c t}$ over different years for the same individual complicates the proper estimation of our standard errors. Unlike previous

\footnotetext{
${ }^{13}$ Clearly, the previous studies that have restricted their observation of offspring's income to certain ages have similarly relied on an assumption of common life-cycle trajectories across cohorts.
} 
authors who discarded all observations except one for each individual, we use all the available information, but apply standard methods of robust covariance matrix estimation to correct our standard error estimates. In particular, we use the robust covariance matrix estimator described on page 330 of Wooldridge (2002). Although Wooldridge's discussion on that page is motivated by the dependence among error terms for different individuals within the same geographic cluster, the same approach applies to the serial correlation among error terms in different time periods for the same individual. The robust covariance matrix estimator corrects not only for serial correlation, but for heteroskedasticity as well.

\section{Results}

The second column of table 1 shows our estimates of the intergenerational income elasticity $\beta_{t}$ for sons in each available year from 1977 through 2000 . As explained above, although these estimates are based on multiple cohorts, they are normalized in terms of the elasticity for 40 -year-olds in each year. As shown by the standard error estimates in parentheses, the elasticity estimates for the early years are relatively imprecise because they are based on small samples of sons still in their twenties. Over time, as more cohorts age into our sample, the elasticity estimates become more precise. ${ }^{14}$

The simple average of the 22 year-specific estimates is 0.44 , a fairly typical estimate relative to the relevant literature surveyed in Solon (1999). Every one of the year-specific estimates is within 0.10 of that average. The black line connecting the

\footnotetext{
${ }^{14} \mathrm{Had}$ we parameterized trends in terms of cohorts instead of years, the same pattern would have appeared as relatively imprecise estimates for later cohorts, which are observed for fewer years. Either way, the same phenomenon is similarly manifested once one contrasts the elasticity estimates either between earlier and later years or between earlier and later cohorts.
} 
diamond-shaped data points in figure 1 plots the time series of the year-specific estimates. Visual inspection of the plot suggests no clear-cut trend. ${ }^{15}$ The last row in table 1 displays the Wald statistic (based on the robust covariance matrix estimate) for testing the null hypothesis that all 22 of the year-specific elasticities are the same. As one might guess from viewing figure 1 , the test does not reject that hypothesis at conventional significance levels.

The second column of table 2 displays the corresponding estimates for daughters. The simple average of the year-specific estimates is 0.43 . In the case of daughters, the relatively imprecise estimates for the early years are way below that average. Once more cohorts have joined the sample by 1983, all the subsequent estimates lie between 0.43 and 0.56. Visual inspection of the black line connecting the diamond-shaped data points in figure 2 suggests no clear-cut trend from 1983 on. The Wald statistic in the bottom row of table 2 rejects the null hypothesis of equal elasticities at the 0.05 significance level, mainly because of the lower estimates in the early years. We are reluctant, however, to conclude that the elasticity for daughters truly increased from 1977 to 1983. Not only are our estimates for that period based on small samples, but they also rely especially heavily on our method for extrapolating elasticities for daughters in their twenties to elasticities at other ages.

Notwithstanding our concern about that extrapolation, we still believe that the efficiency payoff from using all available data is considerable. To highlight that payoff, in the third column of tables 1 and 2, we imitate Mayer and Lopoo's $(2004,2005)$ practice of using observations only at age 30 and discarding the rest of the data. The

\footnotetext{
${ }^{15}$ Ordinary least squares fitting of a linear time trend through the plotted time series yields an estimated time coefficient of -0.0004 , implying that the intergenerational elasticity declined by less than 0.01 from 1977 to 2000.
} 
estimated regression is the same as equation (1) except that we no longer need any of the controls involving child's age $t-c-40$. The time series of resulting elasticity estimates begins in 1982, the year that the 1952 cohort reaches age 30 . The samples of 30 -yearolds average less than 50 per year, so it is unsurprising that the standard error estimates are larger than those for our full-sample estimates. ${ }^{16}$ As can be seen by eyeballing the estimates in the third column or the corresponding plots in figures 1 and 2 , the estimates are wildly volatile, ranging from -0.39 to 0.75 (in adjacent years!) for sons and from 0.14 to 1.02 for daughters. The remaining columns of tables 1 and 2 and the other lines in figures 1 and 2 show the results of estimating elasticities using data on only 29 -year-olds or 28-year-olds. Again the estimates are subject to large standard errors and are wildly volatile. Obviously, the large fluctuations are driven mainly by sampling error, not by actual changes in the population.

As noted above, our main specification shown in equation (1) assumes that the shape of the income/age trajectory is the same for every cohort. We have checked the sensitivity of our results to that assumption by expanding the vector of explanatory variables to include interactions of the year dummies with a linear age term. Somewhat surprisingly, in the analyses for both sons and daughters, a Wald test of the null hypothesis of zero coefficients for all the additional explanatory variables fails to reject that null hypothesis at any conventional significance level. More importantly, the

\footnotetext{
${ }^{16}$ Mayer and Lopoo's yearly numbers of cases are somewhat larger because they include the Survey of Economic Opportunity (SEO) subsample. That cannot greatly improve the precision of their estimation, however, because they downweight the extra observations to offset the resulting oversampling of lowincome families. Mayer and Lopoo do not indicate whether their standard error estimates are corrected for the heteroskedasticity induced by the weighting. See Wooldridge (1999) for an explanation of why the correction is needed. As discussed in footnote 6, we prefer not to use the SEO subsample at all because of the serious irregularities in its selection.
} 
inclusion of the additional explanatory variables produces very little change in our estimated time series of the intergenerational elasticities for either gender.

Compared to previous studies, our approach of using data for all available ages improves the precision of the estimation of intergenerational elasticities over time, but it does so at a cost: the additional complexity associated with our model's elaborate controls for the offspring's stage of life cycle makes it harder to understand what patterns in the data drive our results. To gain a more direct view of the basis for our results, for each overlapping five-year birth cohort (1952-1956, 1953-1957, ..., 1971-1975) we have estimated separate regressions of son's or daughter's log income in each available year from 1981 through 2000 on parental log income and parental age controls. Tables 3 and 4 provide a partial summary of the results.

For example, the first entry in table 3 , the 0.31 figure for sons aged 25-29 in 1981-1985, is the simple average of the five estimated elasticities for the 1952-1956 birth cohort in 1981, the 1953-1957 cohort in 1982, ..., the 1956-1960 cohort in 1985. Similarly, the 0.44 entry for ages 30-34 in 1986-1990 is the simple average of the five estimated elasticities for the 1952-1956 cohort in 1986 through the 1956-1960 cohort in 1990. The purpose of the averaging across five adjacent birth cohorts and five adjacent years is to average out some of the noise from sampling error.

The advantage of tables 3 and 4 is that they enable a straightforward eyeballing of patterns across time periods, cohorts, and ages. Reading each table diagonally from northwest to southeast follows the evolution of a cohort's elasticity estimates over time (and over the life cycle). Reading a column vertically compares elasticity estimates of younger and older cohorts within a time period. Reading a row horizontally holds age 
constant and views the evolution of that age group's elasticity estimates as different cohorts pass through that age interval over time.

In accordance with the previous literature's finding that intergenerational income elasticity estimates come out lower when son's income is measured early in the life cycle, viewing table 3 diagonally shows a clear tendency for cohorts' estimated elasticities to rise as they age from their twenties to thirties. Viewing the table vertically shows the same life-cycle pattern for younger vs. older cohorts within time period. These patterns are less clear-cut in table 4 for daughters. In both tables, however, a horizontal reading of estimates across time holding age constant reveals no consistent trend. This is the source of our model-based results in tables 1 and 2 and figures 1 and 2 that display no obvious time (or cohort) trend in intergenerational mobility.

To summarize, previous estimates of trends in intergenerational mobility have yielded widely divergent results, partly because of the imprecision resulting from sparse samples. By making more efficient use of the available data from the Panel Study of Income Dynamics, we are able to obtain more reliable evidence. Our estimates are still too imprecise to rule out modest trends in either direction. For the most part, though, our results for the cohorts born between 1952 and 1975 suggest that intergenerational income mobility in the United States has not changed dramatically over the last two decades. 
Table 1. Estimated Intergenerational Income Elasticities by Year for Sons

\begin{tabular}{|c|c|c|c|c|}
\hline Year & $\begin{array}{l}\text { Estimates from } \\
\text { Full Sample }\end{array}$ & $\begin{array}{c}\text { Estimates } \\
\text { Based on Only } \\
\text { 30-Year-Olds }\end{array}$ & $\begin{array}{l}\text { Estimates } \\
\text { Based on Only } \\
29-\text { Year-Olds }\end{array}$ & $\begin{array}{c}\text { Estimates } \\
\text { Based on Only } \\
28 \text {-Year-Olds }\end{array}$ \\
\hline 1977 & $0.34(0.20)$ & & & \\
\hline 1978 & $0.54(0.13)$ & & & \\
\hline 1979 & $0.50(0.15)$ & & & \\
\hline 1980 & $0.48(0.13)$ & & & $0.22(0.16)$ \\
\hline 1981 & $0.42(0.14)$ & & $0.09(0.15)$ & $0.11(0.23)$ \\
\hline 1982 & $0.52(0.12)$ & $0.36(0.16)$ & $0.33(0.18)$ & $0.46(0.16)$ \\
\hline 1983 & $0.46(0.11)$ & $0.24(0.22)$ & $0.37(0.16)$ & $0.32(0.16)$ \\
\hline 1984 & $0.39(0.11)$ & $0.52(0.16)$ & $0.37(0.17)$ & $0.08(0.16)$ \\
\hline 1985 & $0.41(0.12)$ & $0.43(0.17)$ & $0.24(0.16)$ & $0.23(0.20)$ \\
\hline 1986 & $0.47(0.10)$ & $0.53(0.18)$ & $0.37(0.21)$ & $0.60(0.17)$ \\
\hline 1987 & $0.41(0.12)$ & $0.50(0.23)$ & $0.49(0.16)$ & $0.54(0.21)$ \\
\hline 1988 & $0.38(0.09)$ & $0.28(0.19)$ & $1.14(0.25)$ & $0.02(0.18)$ \\
\hline 1989 & $0.42(0.09)$ & $0.75(0.24)$ & $-0.06(0.19)$ & $0.30(0.16)$ \\
\hline 1990 & $0.36(0.08)$ & $-0.39(0.23)$ & $0.35(0.15)$ & $0.27(0.16)$ \\
\hline 1991 & $0.43(0.08)$ & $0.42(0.16)$ & $0.23(0.16)$ & $0.23(0.17)$ \\
\hline 1992 & $0.45(0.08)$ & $0.24(0.16)$ & $0.32(0.18)$ & $0.14(0.15)$ \\
\hline 1993 & $0.49(0.08)$ & $0.31(0.15)$ & $0.05(0.16)$ & $0.36(0.18)$ \\
\hline 1994 & $0.43(0.07)$ & $0.27(0.15)$ & $0.02(0.18)$ & $0.90(0.19)$ \\
\hline 1995 & $0.40(0.07)$ & $0.03(0.17)$ & $0.70(0.20)$ & $0.27(0.14)$ \\
\hline 1996 & $0.43(0.07)$ & $0.71(0.19)$ & $0.44(0.14)$ & $0.22(0.18)$ \\
\hline 1998 & $0.47(0.06)$ & $0.44(0.18)$ & $0.10(0.19)$ & $0.56(0.12)$ \\
\hline 2000 & $0.49(0.06)$ & $0.50(0.15)$ & $0.65(0.15)$ & $0.16(0.14)$ \\
\hline $\begin{array}{l}\text { Number of } \\
\text { observations }\end{array}$ & 11,230 & 760 & 814 & 853 \\
\hline $\begin{array}{l}\text { Statistic for } \\
\text { testing equality } \\
\text { of elasticities } \\
\text { across years }\end{array}$ & $\begin{array}{l}\text { Wald statistic } \\
\quad=26.75 \\
(\mathrm{p}=0.18)\end{array}$ & $\begin{array}{l}\mathrm{F}(16,722) \\
\quad=1.59 \\
(\mathrm{p}=0.07)\end{array}$ & $\begin{array}{l}\mathrm{F}(17,774) \\
\quad=2.10 \\
(\mathrm{p}=0.01)\end{array}$ & $\begin{array}{l}\mathrm{F}(18,811) \\
\quad=1.56 \\
(\mathrm{p}=0.06)\end{array}$ \\
\hline
\end{tabular}

Note: The parenthesized numbers next to the elasticity estimates are standard error estimates. As explained in the text, the standard error estimates for the full-sample estimates are robust to the serial correlation resulting from repeated observations of the same individuals. 
Table 2. Estimated Intergenerational Income Elasticities by Year for Daughters

\begin{tabular}{|c|c|c|c|c|}
\hline Year & $\begin{array}{l}\text { Estimates from } \\
\text { Full Sample }\end{array}$ & $\begin{array}{c}\text { Estimates } \\
\text { Based on Only } \\
30-\text { Year-Olds }\end{array}$ & $\begin{array}{c}\text { Estimates } \\
\text { Based on Only } \\
\text { 29-Year-Olds }\end{array}$ & $\begin{array}{c}\text { Estimates } \\
\text { Based on Only } \\
\text { 28-Year-Olds }\end{array}$ \\
\hline 1977 & $0.05(0.17)$ & & & \\
\hline 1978 & $0.19(0.13)$ & & & \\
\hline 1979 & $0.20(0.12)$ & & & \\
\hline 1980 & $0.27(0.11)$ & & & $0.22(0.15)$ \\
\hline 1981 & $0.37(0.11)$ & & $0.48(0.15)$ & $0.13(0.16)$ \\
\hline 1982 & $0.37(0.11)$ & $0.40(0.17)$ & $0.35(0.16)$ & $0.17(0.15)$ \\
\hline 1983 & $0.45(0.11)$ & $0.40(0.14)$ & $0.50(0.16)$ & $0.29(0.17)$ \\
\hline 1984 & $0.49(0.10)$ & $0.61(0.15)$ & $0.43(0.18)$ & $0.50(0.17)$ \\
\hline 1985 & $0.53(0.10)$ & $0.41(0.17)$ & $0.58(0.17)$ & $0.49(0.18)$ \\
\hline 1986 & $0.49(0.10)$ & $0.49(0.16)$ & $0.68(0.19)$ & $0.11(0.18)$ \\
\hline 1987 & $0.50(0.09)$ & $0.61(0.20)$ & $0.20(0.17)$ & $0.70(0.14)$ \\
\hline 1988 & $0.54(0.09)$ & $0.41(0.17)$ & $0.68(0.14)$ & $0.69(0.19)$ \\
\hline 1989 & $0.56(0.08)$ & $0.73(0.16)$ & $0.69(0.17)$ & $0.43(0.17)$ \\
\hline 1990 & $0.52(0.07)$ & $1.02(0.20)$ & $0.68(0.20)$ & $0.55(0.14)$ \\
\hline 1991 & $0.53(0.07)$ & $0.51(0.20)$ & $0.56(0.15)$ & $0.34(0.18)$ \\
\hline 1992 & $0.49(0.07)$ & $0.65(0.14)$ & $0.39(0.20)$ & $0.18(0.12)$ \\
\hline 1993 & $0.50(0.07)$ & $0.14(0.19)$ & $0.12(0.16)$ & $0.43(0.17)$ \\
\hline 1994 & $0.48(0.07)$ & $0.22(0.14)$ & $0.58(0.18)$ & $0.47(0.14)$ \\
\hline 1995 & $0.48(0.06)$ & $0.58(0.19)$ & $0.50(0.14)$ & $0.57(0.14)$ \\
\hline 1996 & $0.43(0.06)$ & $0.54(0.14)$ & $0.43(0.14)$ & $0.19(0.14)$ \\
\hline 1998 & $0.45(0.05)$ & $0.33(0.13)$ & $0.31(0.21)$ & $0.43(0.14)$ \\
\hline 2000 & $0.46(0.06)$ & $0.47(0.14)$ & $0.39(0.15)$ & $0.53(0.13)$ \\
\hline $\begin{array}{l}\text { Number of } \\
\text { observations }\end{array}$ & 12,666 & 849 & 915 & 964 \\
\hline $\begin{array}{l}\text { Statistic for } \\
\text { testing equality } \\
\text { of elasticities } \\
\text { across years }\end{array}$ & $\begin{array}{l}\text { Wald statistic } \\
\quad=33.34 \\
(\mathrm{p}=0.04)\end{array}$ & $\begin{array}{l}\mathrm{F}(16,811) \\
=1.38 \\
(\mathrm{p}=0.14)\end{array}$ & $\begin{array}{l}\mathrm{F}(17,875) \\
\quad=0.96 \\
(\mathrm{p}=0.51)\end{array}$ & $\begin{array}{l}\mathrm{F}(18,922) \\
\quad=1.51 \\
(\mathrm{p}=0.08)\end{array}$ \\
\hline
\end{tabular}

Note: See note in table 1. 
Table 3. Estimated Intergenerational Income Elasticities by Age Group for Sons Averaged over Five-Year Periods

\begin{tabular}{lcccc}
\hline Age Range & $1981-1985$ & $1986-1990$ & $1991-1995$ & $\begin{array}{c}1996,1998, \\
\end{array}$ \\
\hline $25-29$ & 0.31 & 0.20 & 0.35 & 0.32 \\
$30-34$ & & 0.44 & 0.38 & 0.45 \\
$35-39$ & & & 0.48 & 0.45 \\
$40-44$ & & & & 0.40 \\
\hline
\end{tabular}


Table 4. Estimated Intergenerational Income Elasticities by Age Group for Daughters Averaged over Five-Year Periods

\begin{tabular}{lcccc}
\hline Age Range & $1981-1985$ & $1986-1990$ & $1991-1995$ & $\begin{array}{c}1996,1998, \\
2000\end{array}$ \\
\hline $25-29$ & 0.40 & 0.52 & 0.40 & 0.36 \\
$30-34$ & & 0.47 & 0.48 & 0.36 \\
$35-39$ & & & 0.46 & 0.51 \\
$40-44$ & & & & 0.43 \\
\hline
\end{tabular}


Figure 1. Estimated Intergenerational Income Elasticities for Sons, 1977-2000

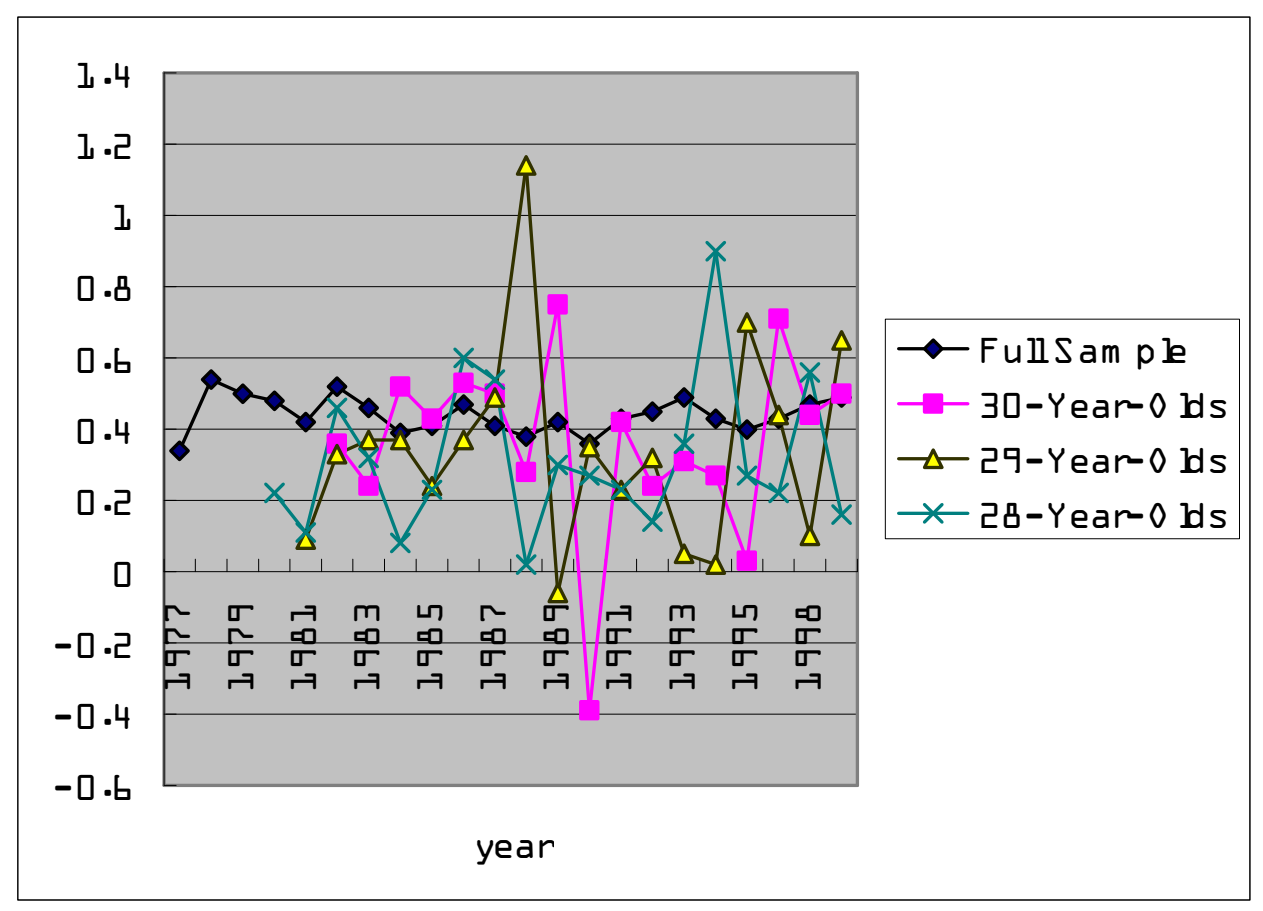


Figure 2. Estimated Intergenerational Income Elasticities for Daughters, 1977-2000

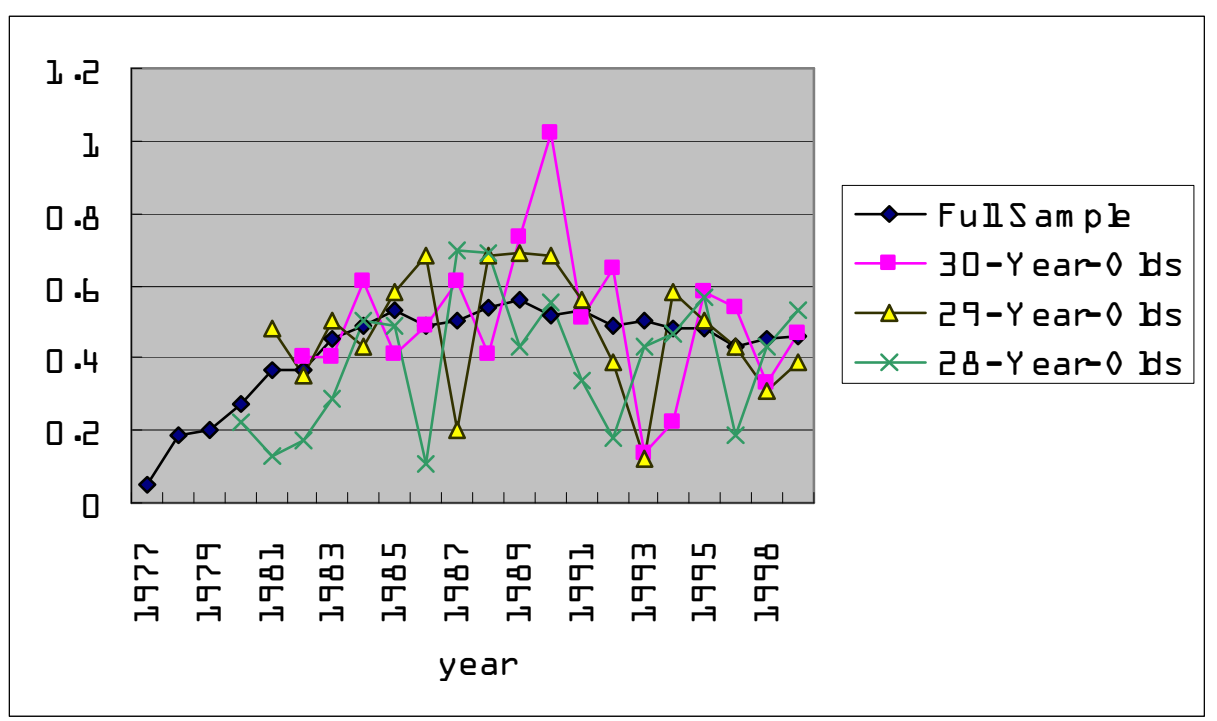




\section{$\underline{\text { References }}$}

Becker, Gary S. and Tomes, Nigel. “An Equilibrium Theory of the Distribution of Income and Intergenerational Mobility.” Journal of Political Economy, December 1979, 87(6), pp. 1153-89.

Bernstein, Aaron. "Waking Up from the American Dream: Dead-End Jobs and the High Cost of College Could Be Choking Off Upward Mobility.” Business Week, December 1, 2003, pp. 54-8.

Blanden, Jo. "International Evidence on Intergenerational Mobility." Unpublished, 2004.

Borjas, George J. "The Intergenerational Mobility of Immigrants.” Journal of Labor Economics, January 1993, 11(1), pp. 113-35.

Card, David, DiNardo, John and Estes, Eugena. "The More Things Change: Immigrants and the Children of Immigrants in the 1940s, the 1970s, and the 1990s," in George J. Borjas, ed., Issues in the economics of immigration. Chicago: University of Chicago Press, 2000, pp. 227-69.

Chadwick, Laura. "Changes in Intergenerational Economic Mobility in the United States." Unpublished, 2004.

Chadwick, Laura and Solon, Gary. "Intergenerational Income Mobility among Daughters." American Economic Review, March 2002, 92(1), pp. 335-44.

Corcoran, Mary. "Mobility, Persistence, and the Consequences of Poverty for Children," in Sheldon H. Danziger and Robert H. Haveman, eds., Understanding poverty. New York: Russell Sage Foundation, 2001, pp. 127-61. 
Deaton, Angus. The analysis of household surveys: a microeconometric approach to development policy. Baltimore: Johns Hopkins University Press, 1997.

Fertig, Angela R. "Trends in Intergenerational Earnings Mobility in the U.S." Journal of Income Distribution, forthcoming.

Gottschalk, Peter and Moffitt, Robert. "The Growth of Earnings Instability in the U.S. Labor Market.” Brookings Papers on Economic Activity, 2:1994, pp. 217-54.

Grawe, Nathan D. "Lifecycle Bias in Estimates of Intergenerational Earnings Persistence.” Labour Economics, forthcoming.

Haider, Steven J. "Earnings Instability and Earnings Inequality of Males in the United States: 1967-1991.” Journal of Labor Economics, October 2001, 19(4), pp. 799836.

Haider, Steven and Solon, Gary. "Life-Cycle Variation in the Association between Current and Lifetime Earnings." American Economic Review, forthcoming. Harding, David J., Jencks, Christopher, Lopoo, Leonard M. and Mayer, Susan E. "The Changing Effects of Family Background on the Incomes of American Adults," in Samuel Bowles, Herbert Gintis and Melissa Osborne Groves, eds., Unequal chances: family background and economic success. New York: Russell Sage Foundation, 2005, pp. 100-44.

Hauser, Robert M. "Intergenerational Economic Mobility in the United States: Measures, Differentials, and Trends.” Unpublished, 1998.

Hertz, Tom. "Attrition- and Age-Bias-Corrected Estimates of the Trend in the Intergenerational Persistence of Family Income.” Unpublished, 2005. 
Katz, Lawrence F. and Autor, David H. "Changes in the Wage Structure and Earnings Inequality," in Orley C. Ashenfelter and David Card, eds., Handbook of labor economics, Vol. 3A. Amsterdam: North-Holland, 1999, pp. 1463-555.

Levine, David I. and Mazumder, Bhashkar. "Choosing the Right Parents: Changes in the Intergenerational Transmission of Inequality between 1980 and the Early 1990s.” Working Paper No. 2002-08, Federal Reserve Bank of Chicago, 2002.

Mayer, Susan E. and Lopoo, Leonard M. "What Do Trends in the Intergenerational Economic Mobility of Sons and Daughters in the United States Mean?” in Miles Corak, ed., Generational income mobility in North America and Europe. Cambridge: Cambridge University Press, 2004, pp. 90-121.

Mayer, Susan E. and Lopoo, Leonard M. "Has the Intergenerational Transmission of Economic Status Changed?” Journal of Human Resources, Winter 2005, 40(1), pp. 169-85.

Mazumder, Bhashkar. "Fortunate Sons: New Estimates of Intergenerational Mobility in the U.S. Using Social Security Earnings Data." Review of Economics and Statistics, May 2005, 87(2), pp. 235-55.

Murphy, Kevin M. and Welch, Finis. "Empirical Age-Earnings Profiles.” Journal of Labor Economics, April 1990, 8(2), pp. 202-29.

Nam, Yunju. "Is America Becoming More Equal for Children? Changes in the Intergenerational Transmission of Low- and High-Income Status.” Social Science Research, June 2004, 33(2), pp. 187-205.

Reville, Robert T. "Intertemporal and Life Cycle Variation in Measured Intergenerational Earnings Mobility.” Unpublished, 1995. 
Scott, Janny and Leonhardt, David. "Class in America: Shadowy Lines That Still Divide." New York Times, May 15, 2005, pp. 1 and 16-8.

Solon, Gary. "Biases in the Estimation of Intergenerational Earnings Correlations." Review of Economics and Statistics, February 1989, 71(1), pp. 172-4.

Solon, Gary. "Intergenerational Mobility in the Labor Market," in Orley C. Ashenfelter and David Card, eds., Handbook of labor economics, Vol. 3A. Amsterdam: North-Holland, 1999, pp. 1761-800.

Solon, Gary. “A Model of Intergenerational Mobility Variation over Time and Place,” in Miles Corak, ed., Generational income mobility in North America and Europe. Cambridge, UK: Cambridge University Press, 2004, pp. 38-47.

Welch, Finis. "In Defense of Inequality.” American Economic Review, May 1999, 89(2), pp. 1-17.

Wessel, David. "Moving Up: Challenges to the American Dream." Wall Street Journal, May 13, 2005, p. A1.

Wooldridge, Adrian. "Ever Higher Society, Ever Harder to Ascend.” Economist, January 1, 2005, pp. 22-4.

Wooldridge, Jeffrey M. “Asymptotic Properties of Weighted M-Estimators for Variable Probability Samples.” Econometrica, November 1999, 67(6), pp. 1385-1406.

Wooldridge, Jeffrey M. Econometric analysis of cross section and panel data. Cambridge, MA: MIT Press, 2002. 